\title{
O ACERVO DO LABORATÓRIO DE MATEMÁTICA DO INSTITUTO DE EDUCAÇÃO GENERAL FLORES DA
} CUNHA

\section{THE MATHEMATICS LABORATORY COLLECTION OF THE GERNERAL FLORES DA CUNHA EDUCATION INSTITUTE}

\author{
Andréia Dalcin* \\ Maria Cecilia Bueno Fischer**
}

“Ao sermos apresentados à ampla sala denominada de "laboratório de matemática”, os sentimentos de curiosidade, surpresa e alegria foram intensos, assim como o cheiro do tempo, que se manifestava no pó dos livros, textos mimeografados antigos, nos materiais guardados nos armários, no mofo da sala

\footnotetext{
* Universidade Federal do Rio Grande do Sul (UFRGS), Porto Alegre/RS, Brasil.

${ }^{* *}$ Universidade Federal do Rio Grande do Sul (UFRGS), Porto Alegre/RS, Brasil.
} 
que carece de pintura e reparos”. (DALCIN, 2016, p. 46).

A partir da atuação do subprojeto matemática do Pibid (Programa Institucional de Bolsas de Iniciação à Docência) da UFRGS no Instituto de Educação General Flores da Cunha (Iegfc), Porto Alegre, em 2014, tivemos contato com o acervo do Laboratório de Matemática do Instituto. Inicialmente localizado na ampla sala do Laboratório, o acervo constituía-se em um conjunto de livros e documentos impressos, mimeografados ou manuscritos e materiais didáticos, na maioria de madeira, todos armazenados em 7 armários que ficavam ao fundo da sala, que nada mais era do que um depósito de livros didáticos, muitos ainda embalados, oriundos do Programa Nacional do Livro Didático. Os estudos nos mostraram que, no Laboratório de Matemática, inaugurado em 1956, foram desenvolvidas inúmeras atividades e produções ao longo dos anos 1960 e 1970, tendo um papel de destaque no cenário local e nacional, como um espaço de formação de professores que ensinavam matemática, frequentado, principalmente, por estudantes e professores do Curso Normal. Este espaço, que fora um importante laboratório de matemática, caiu no esquecimento, e tornouse um depósito, há pelo menos três décadas. Logo evidenciamos que mais do que livros, papel, pó e mofo, o local guardava memórias e evidências de um outro tempo, que precisava ser (re)conhecido e estudado.

Por conta do processo de restauro do prédio do Iegfc, o material do Laboratório foi deslocado para o Instituto de Matemática e Estatística (IME) da UFRGS, ficando sob a responsabilidade das pesquisadoras Andréia Dalcin, Elisabete Zardo Búrigo e Maria Cecilia Bueno Fischer, todas integrantes do Programa de Pós-Graduação em Ensino de Matemática e pesquisadoras na área de História da Educação Matemática.

Com a aprovação do projeto "Estudar para ensinar: práticas e saberes matemáticos nas escolas normais do Rio Grande do Sul (1889-1970)” pelo CNPq, em maio de 2017, iniciou-se o trabalho de organização, higienização, catalogação e, mais recentemente, digitalização do acervo do Laboratório. Os recursos do projeto permitiram a compra de materiais próprios para o desenvolvimento 
dessas etapas, como luvas, máscaras, papel de seda, pastas, scanner, entre outros, além da constituição de uma equipe de bolsistas de Iniciação Científica, de Extensão e de alguns estudantes voluntários.

Todo o material do acervo foi depositado na sala B123 do IME, onde começou-se o trabalho de organização e higienização, sendo o material, conforme a tipologia, disposto em caixas ou embrulhados em papel de seda, acondicionados nos armários, como se pode visualizar nas imagens da Figura 1.

Figura 1 - Sala B123 (IME/UFRGS)
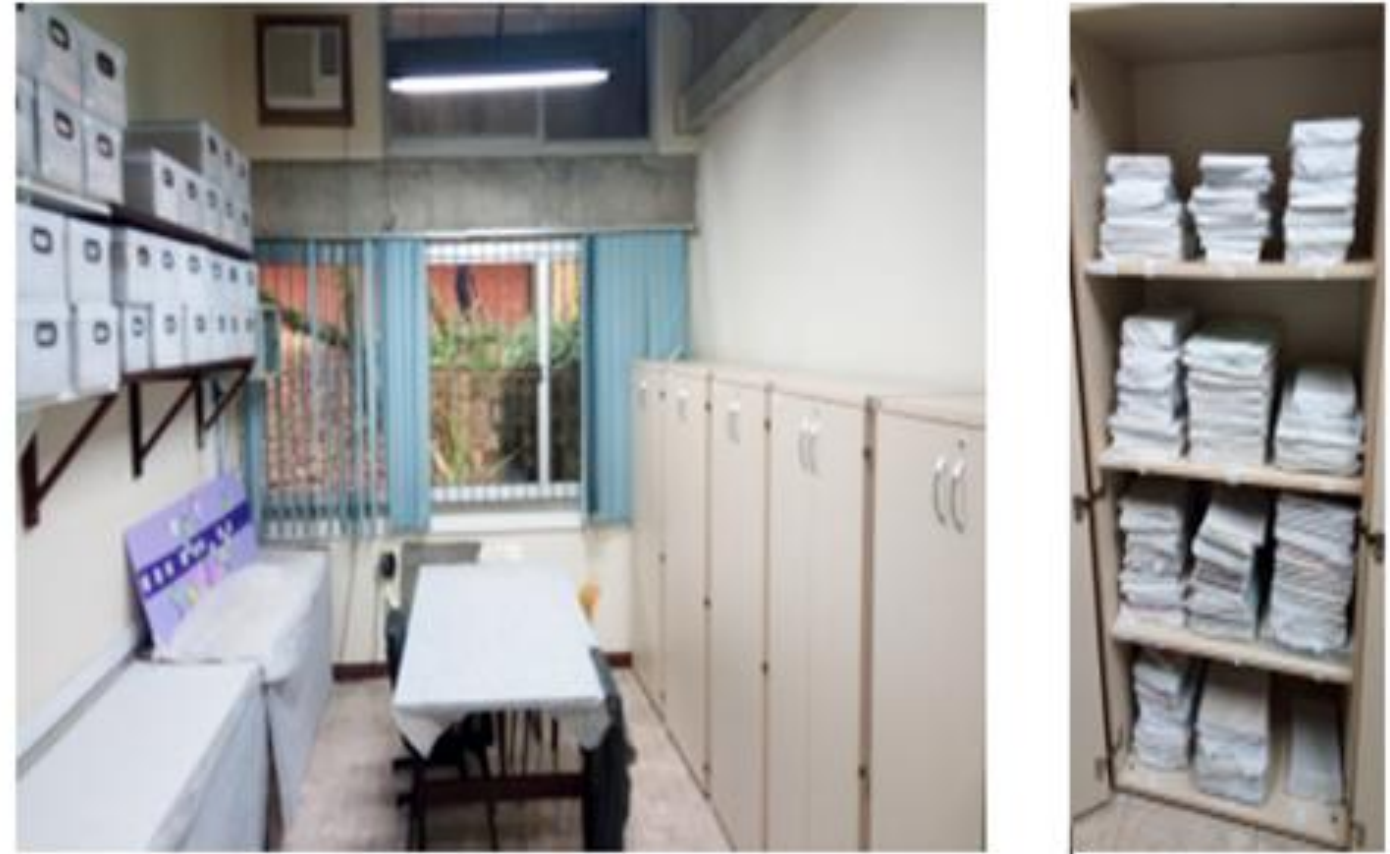

Fonte: Acervo das autoras.

Para cada documento, foi produzida uma ficha com dados e informações sobre o estado físico, a natureza e o conteúdo do material. Devido aos recursos financeiros do projeto, nem sempre foi possível escolher a melhor ou a mais adequada opção para o acondicionamento do material. Referimo-nos às caixas polionda, o papel de seda, o uso de cordas de algodão para embalar cada documento e guardar nas caixas ou nos armários, as condições de umidade da 
sala, entre outros cuidados. São escolhas que tivemos que fazer, procedimentos que tiveram que ser aprendidos, dado que não temos formação em Arquivologia, Museologia ou Biblioteconomia. Somos oriundas da área de Educação Matemática e pesquisadoras no campo da História da Educação Matemática, sendo o trabalho com acervos e arquivos escolares algo novo. Tivemos que nos apropriar de procedimentos e conceitos próprios. Nesse sentido, ao iniciarmos a etapa de digitalização dos documentos higienizados, contamos com a parceria do Centro de Documentação de Acervo Digital da Pesquisa da UFRGS (Cedap), fundamental para o processo de digitalização do material selecionado. O Cedap possui equipamentos que permitem efetuar a digitalização com alta qualidade, o que viabilizará a constituição de uma coleção a ser disponibilizada no repositório digital Lume, da UFRGS.

Estamos realizando o que nos aponta Certeau: "em história, tudo começa com o gesto de separar, de reunir, de transformar em "documentos" certos objetos distribuídos de outra maneira. Esta nova distribuição cultural é o primeiro trabalho" (CERTEAU, 2002, p. 81). Cada folha de papel, livro, modelo de prova, trabalho de normalistas, material didático, anotação de professor, plano de aula ou modelo de atividade, é um documento histórico que poderá vir a constituir-se como uma fonte para um pesquisador que perceba o potencial do documento para sua pesquisa. São documentos produzidos na escola, por professores e alunos, objetos materiais e simbólicos com intencionalidades, elaborados em um contexto de tempo e espaço específicos. No entanto, mais do que separar, organizar e reunir, é preciso "interpretar" e "ler" cada documento, dialogar com ele, constituí-lo como fonte, efetivamente. Mais do que informações, os documentos trazem inúmeras possibilidades de construção e (re)construção de narrativas históricas.

Os documentos localizados no acervo do Laboratório de Matemática nos permitem adentrar na escola, trazem rastros e indícios das práticas que lá aconteciam; estão impregnados de informações sobre professores e professoras, sua rotina, a organização do tempo, do espaço e dos modos de ensinar. Podem 
fornecer "[...] elementos para a reflexão sobre o passado da instituição, das pessoas que a frequentaram ou frequentam, das práticas que nela se produziram e, mesmo, sobre as relações que estabeleceu e estabelece com seu entorno (a cidade e a região na qual se insere)" (VIDAL, 2005, p. 24).

Organizamos, inicialmente, os documentos que integram o acervo em grupos, de acordo com a tipologia: livros, traduções, relatórios, registros de professores e de alunos e provas. É possível que algum novo tipo seja incluído nessa organização, a partir da leitura e interpretação de alguns materiais ainda a analisar. Referimo-nos, especialmente, ao conjunto de folhas, muitas delas soltas, contidas nas inúmeras caixas do acervo que, atualmente, estão em processo de digitalização.

O acervo conta com 680 livros, publicados entre 1938 e 2000, na grande maioria relacionados com a Matemática. Há também livros de psicologia, literatura e ensino. Consultando as fichas de identificação dos documentos, constatamos que há 59 livros de autoria de Zoltan Paul Dienes, 39 livros de Nicole Picard, 37 livros de Scipione di Pierro Neto e 10 livros de Jean Piaget. A maioria deles é dos anos 1960 a 1970, são mais de 300 livros publicados nesse período. Esse período coincide com o auge do Movimento da Matemática Moderna, em que tivemos muitas publicações feitas com o objetivo de disseminar o ideário do movimento. Além disso, no caso de Dienes, temos o registro de sua presença em Porto Alegre nos anos 1970, tendo atuado com professor do Instituto de Educação Flores da Cunha, o que pode ter contribuído para essa quantidade de livros. Piaget e Picard, de acordo com os estudos de Bonfada (2017), são autores que foram estudados pelos professores nos encontros do Círculo de Estudos de Matemática, que aconteciam no Laboratório de Matemática do Instituto. A maioria dos livros foi publicada no Brasil, mas encontram-se também obras publicadas principalmente na França.

Além dos livros, merece destaque a presença, no acervo, de diversos materiais didáticos manipuláveis. Pelos registros encontrados e a partir dos estudos já realizados, pode-se dizer que muitas das atividades propostas pelo 
Laboratório privilegiavam o uso de materiais para o ensino e a aprendizagem de Matemática.

Entre os materiais já estudados, podemos citar o Cuisenaire, composto por dez tipos de peças de cores e tamanhos diferentes. No acervo, foram encontrados três conjuntos, feitos de madeira. Com o material, pode-se estudar diversos conteúdos matemáticos, como a soma, adição, multiplicação, divisão, frações e conjuntos (ROSA; SILVA, 2019).

Outro material encontrado no acervo foi uma caixa, identificada como Quadrimath. Dentro da caixa, além de diversas peças dos jogos Trimath $e$ Quadrimath, encontra-se o livro Trimath Quadrimath jeux logiques, ensemblistes et géométriques, de Peter Seaborne, e cópias de traduções dele, mimeografadas. Os jogos são compostos por peças de formato triangular, quadrangular, pentagonal ou hexagonal, com variadas quantidades de furos e de cores, permitindo explorar vários conceitos matemáticos, como comparação, relações de ordem, de equivalência, operações, conjuntos, simetria e rotação, entre outros (SAUTER; FISCHER, 2019).

Há materiais que foram confeccionados pela equipe do Laboratório, coordenada pela professora Odila de Barros Xavier, como é o caso de um material identificado como um filme, denominado As frações da vida diária da criança. O filme consiste em uma sequência de folhas de papel com diversas imagens, coladas lado a lado e dobradas como uma "sanfona". As imagens apresentam situações variadas do dia a dia, que podem ser representadas por frações (SOUZA; FISCHER; LIMA; SEVERO, 2019).

Tais materiais nos dão indícios de práticas desenvolvidas na formação de estudantes da Escola Normal, bem como no ensino de alunos e alunas do Instituto de Educação, no que se refere à Matemática. São integrantes do patrimônio escolar, que "não pode ser visto como um conjunto de objectos folclóricos de um passado que se desconhece, mas tem de ser integrado na transformação dos contextos escolares e da relação da docência com a cultura" (FELGUEIRAS, 2005, p. 98). Essa aproximação aos materiais que compõem o 
acervo do Laboratório nos ajuda a viajar entre o passado e o futuro, para, quem sabe, mudarmos o presente ou a visão que dele temos, como nos aponta Felgueiras (2005).

Além de livros e materiais didáticos, o acervo conta com uma grande quantidade de folhas de papel, acondicionadas inicialmente em caixas de papelão. As folhas tratam de atividades de aula, traduções, anotações de professores, provas, entre outros. Tais materiais nos dão indícios sobre o que era desenvolvido no Laboratório de Matemática, ao longo de sua trajetória. Como expressa bem a professora Odila, fundadora e por muitos anos coordenadora do Laboratório, ao analisar o papel desse espaço na escola: “a atividade mais expressiva do Laboratório foi justamente a que não podemos expressar em números porque a vivemos e vimos os outros viverem intensamente, que ficou conhecido como o espírito do Laboratório" (XAVIER, 1963). Espírito esse que buscamos compreender à luz dos documentos que permaneceram e das evidências que produzem e que nos permitem construir histórias.

Como procurou-se relatar neste breve texto, o acervo do Laboratório de Matemática do IEFGC nos brinda com uma riqueza de documentos, cuja organização e posterior disponibilização ao público permitirá conhecer um pouco mais da história da Educação Matemática no Rio Grande do Sul.

\section{REFERÊNCIAS}

BONFADA, Elisete Maria. A Matemática na Formação das Professoras Normalistas: o Instituto de Educação General Flores da Cunha em tempos de Matemática Moderna. 2017. 206f. Dissertação (Mestrado Profissional em Ensino de Matemática) -Programa de Pós-Graduação em Ensino de Matemática, Universidade Federal do Rio Grande do Sul (UFRGS), Porto Alegre, 2017.

CERTEAU, Michel de. A Escrita da História. Rio de Janeiro: Forence Universitária, 2002. 
FELGUEIRAS, Margarida Louro. Materialidade da cultura escolar. A importância da museologia na conservação/comunicação da herança educativa. Pro-Posições. v. 16, n. 1 (46), p. 87-102. jan./abr. 2005.

SILVA, Mayara Becker Oliveira da; ROSA, Nicolas Giovani. Material Cuisenaire: o uso de barras coloridas no ensino de matemática nos anos 1960 em um Instituto de Educação. In: SEMINÁRIO PRÁTICAS E SABERES MATEMÁTICOS NAS ESCOLAS NORMAIS DO RIO GRANDE DO SUL, 2., 2019, Pelotas. Anais ... Porto Alegre: UFRGS, 2019. p.101-114. Disponível em: www.ufrgs.br/escolasnormais

SAUTER, Leonardo Thomaz; FISCHER, Maria Cecilia Bueno. MATERIAL CONCRETO: Trimath e Quadrimath no Ensino de Matemática. In: XVII Seminário Temático: Materiais Didáticos e História da Educação Matemática, 2019, Aracaju. Anais .... Aracaju, 2019. Disponível em: https://xviiseminariotematico.paginas.ufsc.br/

SOUZA, Jenifer; LIMA, Caroline Ferreira; SEVERO, Andrey de Souza; FISCHER, Maria Cecilia Bueno. A Análise de um Material sobre Frações: um filme de 1955. In: SEMINÁRIO PRÁTICAS E SABERES MATEMÁTICOS NAS ESCOLAS NORMAIS DO RIO GRANDE DO SUL, 2., 2019, Pelotas. Anais ... Porto Alegre: UFRGS, 2019. p. 115-123. Disponível em: www.ufrgs.br/escolasnormais

VIDAL, Diana Gonçalves. Cultura e prática escolares: uma reflexão sobre documentos e arquivos escolares. In: SOUZA, Rosa Fátima; VALDEMARIN, Vera. (Org.) A cultura escolar em debate: questões conceituais, metodológicas e desafios para a pesquisa. Campinas, SP: autores Associados, 2005. Apoio: Unesp/FCLAr, p.3-30.

XAVIER, Odila Barros. Um Problema em Marcha. [Relatório]1963.Acervo do Laboratório de Matemática do Instituto de Educação General Flores da Cunha, Porto Alegre, RS. 
ANDRÉIA DALCIN é mestre em Educação, área de Educação Matemática, e Doutora em Educação pela UNICAMP. Professora do Departamento de Ensino e Currículo - Faculdade de Educação, do Programa de Pós-Graduação em Ensino de Matemática da UFRGS e do Programa de Doutorado em Educação em Ciências e Matemática da REAMEC. É pesquisadora do Grupo de Pesquisa História, Filosofia e Educação Matemática (HIFEM). Tem experiência na área de Educação, com ênfase em Educação Matemática, atuando principalmente nos seguintes temas: ensino de matemática, educação, história e filosofia da matemática e da educação matemática, formação de professores de matemática, ciências e para Educação do Campo.

E-mail: andreia.dalcin@ufrgs.br

(1) http://orcid.org/0000-0003-2488-8801

MARIA CECÍLIA FISCHER é mestre em Matemática pela UFSC e doutora em Educação pela UNISINOS/RS. Docente do Departamento de Matemática do Instituto de Matemática e Estatística e do Programa de Pós-Graduação em Ensino de Matemática da UFRGS. É pesquisadora do Grupo de Pesquisa de História da Educação Matemática (GHEMAT). Tem experiência na área de Educação, com ênfase em Educação Matemática, atuando principalmente nos seguintes temas: ensino de Matemática, formação de professores de matemática e história da educação matemática.

E-mail: cecilia.fischer@ufrgs.br

(b) http://orcid.org/0000-0002-0537-4111

Recebido em: 30 de abril de 2020

Aprovado em: 28de maio de 2020

Editor responsável: Dóris Almeida 